
Revue Revue de l'histoire des religions
de Ihistoire des religions
Théologie politique et sciences sociales : autour d'Erik Peterson (1890-1960)

\title{
Vincent GOOSSAERT, Bureaucratie et salut. Devenir un dieu en Chine
}

Genève, Labor et Fides (« Histoire des religions », 5), 2017

Kyong-Kon Kim

\section{(2) OpenEdition \\ Journals}

Édition électronique

URL : https://journals.openedition.org/rhr/11290

DOI : $10.4000 /$ rhr. 11290

ISSN : $2105-2573$

Éditeur

Armand Colin

Édition imprimée

Date de publication : 1 septembre 2021

Pagination : $547-549$

ISBN : 978-2-200-93377-7

ISSN : 0035-1423

Référence électronique

Kyong-Kon Kim, "Vincent Goossaent, Bureaucratie et salut. Devenir un dieu en Chine », Revue de l'histoire des religions [En ligne], 3 | 2021, mis en ligne le 01 septembre 2021, consulté le 04 octobre 2021. URL http://journals.openedition.org/rhr/11290 ; DOI : https://doi.org/10.4000/rhr.11290

Ce document a été généré automatiquement le 4 octobre 2021.

Tous droits réservés 


\title{
Vincent GOOSSAERT, Bureaucratie et salut. Devenir un dieu en Chine
}

Genève, Labor et Fides (« Histoire des religions », 5), 2017

\author{
Kyong-Kon Kim
}

\section{RÉFÉRENCE}

Vincent GOOSSAERT, Bureaucratie et salut. Devenir un dieu en Chine, Genève, Labor et Fides (« Histoire des religions », 5), 2017, 192 p., 22,5 cm, $19 €$, ISBN 978-2-8309-1629-4.

1 La question des états post mortem et celle du salut, auxquelles tout être humain s'intéresse au moins épisodiquement, constituent, nonobstant l'absence de vérifiabilité des diverses conceptions énoncées par de nombreuses traditions religieuses, l'un des domaines de recherche majeurs, phénoménologiques et/ou ontologiques, des sciences des religions. Or, bien que les représentations de l'au-delà et de soteria d'après les trois enseignements 三教 traditionnels chinois (taoïsme, confucianisme et bouddhisme) soient davantage accessibles au public occidental depuis environ un siècle, les études relatives à la (post-)thanato-sotériologie du point de vue de ce qui est nommé « religion populaire chinoise 中國民間信仰》demeurent plutôt exceptionnelles. En effet, le présent ouvrage de Vincent Goossaert $(=\mathrm{VG})$, issu de ses conférences données dans les Universités de Berkeley, de Princeton et d'Oxford ainsi qu'à l'Academia Sinica à Taipei, s'intéresse notamment aux perceptions sotériologiques conçues dans l'empire du Milieu et vise à mettre en lumière un phénomène fondamental dans ces constructions spirituelles, pourtant négligé dans les études (anthropologiques) précédentes, centrées plutôt sur l'ancestralité et/ou l'aspect samsārique: l'aspiration personnelle de divinisation de soi dans le processus vers latranscendance. Afin d'élucider ce phénomène qui se serait graduellement développé à travers une période bimillénaire, le sinologue français à l'École pratique des hautes études propose un examen historiographique, sur une chronologie longue - de l'Antiquité à la période 
contemporaine - qui intègre les interactions entre cette religion populaire et les trois enseignements traditionnels.

VG relève tout d'abord, outre la création des ancêtres par les hommes puissants dès l'époque des Shang (env. 1600-1046 av. J.-C.), la déification des souverains mythiques et des héros civilisateurs, tels que l'Empereur jaune 黄帝, le Divin laboureur 神農, Yu le Grand 大禹 et alii, sous les Zhou (1045-256 av. J.-C.) et l'invention d'une bureaucratie de l'au-delà, vraisemblablement à l'instar de la bureaucratie mondaine établie dans le contexte de l'essor des États durant la période dite des Royaumes combattants (403-222 av. J.-C.). Or, si cette antique déification introduisit la voie de la divinisation des êtres humains, l'encadrement contraignant des défunts dans une structure bureaucratique cosmique administrée par les dieux fonctionnaires aurait aussi engendré la volonté d'y échapper par l'intermédiaire d'accès à la transcendance, c'est-à-dire un nouvel état ont(olog)ique, dans lequel les êtres humains, vivants ou défunts, acquerraient une liberté totale spatio-temporelle tout en gardant leur identité personnelle, mais dont les dieux, soumis à l'administration céleste, ne pourraient jouir : le salut. D'où l'invention proprement chinoise de l'immortalisation de soi, au plus tard au $\mathrm{IV}^{\mathrm{e}} \mathrm{s}$. av. J.-C., suivie d'une réception favorable des notions bouddhiques indiennes de nirvāṇa et de sukhāvatī, introduites probablement au plus tôt au $\mathrm{I}^{\mathrm{er}} \mathrm{s}$. de notre ère, en tant que moyens d'accès à cette transcendance. Puis, un rapprochement entre la divinisation et l'immortalisation aurait été progressivement opéré au sein des nouveaux mouvements religieux, principalement taoïstes, apparus dès les premiers siècles de notre ère - la voie de la Grande paix 太平道, la voie des Maîtres célestes 天師道, l'école de la Pureté suprême 上清派 et l'école du Joyau sacré 霝寶派-, pour que ces deux voies initialement opposées pussent être envisagées comme une étape préalable de l'idéal spirituel visé ou comme l'état ultime sotériologique lui-même. Enfin, l'intégration de tous les défunts dans le nouveau panthéon officiel centralisé, à la tête duquel se trouva l'Empereur de Jade 玉皇, qui fut mise en œuvre par l'État impérial des Song (960-1279) et les taoïstes d'alors, aurait donné lieu à la divinisation universelle, notamment sur le principe méritocratique, ainsi qu'aux diverses méthodes d'intégration dans le corps des dieux corrects 正神, telles que la canonisation, l'ordination, l'autopromotion, etc., par la suite. Depuis lors, la voie de la divinisation de soi 自化爲神 persisterait en tant qu'élément substantiel, « une forme ou une promesse de salut » (p. 165), et non en tant qu'état de transcendance, parmi les options sotériologiques dans le paysage religieux chinois - l'immortalisation 成仙, le nirvāna 涅槃, la sukhāvatī 淨土 - jusqu'à l'époque contemporaine, malgré une multiple transmutation de régimes politiques.

3 À la lecture de ce nouvel opus de VG, une des rares monographies dans ce domaine publiées en langue française, il convient de souligner avant tout la pertinence de sa méthode de recherche: l'approche historique du phénomène religieux dénommé "désir individuel de la divinisation de soi » et relevé dans un contexte chinois connu, entre autres, pour un aspect socio-culturel qualifié conventionnellement de collectif et d'ancestral. Si le résultat de cette étude, fondé sur l'examen de l'histoire intellectuelle chinoise englobant presque toutes les périodes et toutes les traditions spirituelles, paraît solide, le lecteur s'attendrait à l'annotation de la «masse immense de documents » (p. 24) exposant ce désir, dans la bibliographie, tout comme l'indication des références bibliographiques de certains textes sources cités (cf. p. 21, 22, 24, 34, 35, $43,47,63,64,69,70$, etc.). Quant à l'analyse taxinomique de « salut de quoi, vers quoi et par quoi » (Erlösung wovon, wohin und womit), l'auteur se penche délibérément sur les 
deux derniers aspects sotériologiques (cf.p. 107s.), tandis que l'historien s'intéressera autant aux contextes socio-économico-politique et philosophico-religieux, dans lesquels une telle aspiration à l'escapade vit le jour. Par ailleurs, du point de vue de l'histoire comparée des religions, indiennes et chinoises, l'évolution des procédés sotériologiques ( $c f$. p. 43) des voies externes (yajña, 祭祀, 醮, etc.) vers les voies internes (tapas, 内丹術, etc.) mériterait une observation plus approfondie. La mise en exergue de la similitude structurelle entre le monde des vivants et le monde imaginaire des défunts chinois, en tenant compte du destin des femmes (cf. p. 33s., 38, 46, 52, 81, $104,112,123 s ., 129,161)$ construit principalement par leurs compatriotes masculins, est fort méritoire. De plus, ce livre se révèle comme une invitation à la spéculation sur la traductibilité d'un certain nombre de notions chinoises, indiennes ou néologiques, en l'occurrence shen 神, jing 經, saṃsāra, théologie bouddhique, etc.: le terme multivoque shen pourrait, lui seul, illustrer aisément la singularité anthropo-théo-cosmologique chinoise nécessitant une précaution herméneutique de ne pas s'adonner à l'analogie hâtive avec $\operatorname{dieu}(x) / \operatorname{god}(s)$ (cf. p. 10-14); le même mot jing peut désigner à la fois les textes taoïstes "révélés» et les textes canoniques non révélés, confucéens ou bouddhiques (cf. p.135); le sanskrit saṃsāra ou le chinois 輪迴 se traduira plus adéquatement par «transmigration» et non par «réincarnation» (p. 54, 68, 69), puisque diverses destinées du kāmadhātu, selon la cosmo-sotériologie bouddhique ancienne (cf. p.ex. Le Sangìti sutta [DN 33, 5.4]), comprennent également celles réservées à des êtres asomatiques; le néologisme bouddhologie (p.15) semble plus approprié que l'expression théologie bouddhique (p.68), qui, employée initialement dans le cercle de néo-convertis américains - buddhist theology -, pourrait être perçue comme un oxymoron, même si le terme théologie, dérivé du grec préchrétien $\theta \varepsilon o \lambda o \gamma i ́ \alpha$ (Platon, La République, 379a), peut être apprécié en tant que discours critique et démythifié relatif aux dieux.

Malgré ces quelques remarques de détail, le présent opuscule, dense et enrichissant pleinement "notre vision des conceptions de l'au-delà et du salut dans l'histoire religieuse de la Chine» (p.17), remplit incontestablemełnt l'objectif éditorial de la collection helvétique "Histoire des religions» de promouvoir des réflexions fondamentales disciplinaires. Il élargit aussi considérablement le champ épistémologique de la discipline grâce à son exposé sur un domaine peu accessible issu d'une civilisation extra-occidentale et non monothéiste. Il figurera ainsi promptement parmi les ouvrages de référence en sinologie en général et, plus particulièrement, en histoire de la sotériologie chinoise.

\section{AUTEURS}

\section{KYONG-KON KIM}

Université de Strasbourg. 